\title{
Synaptophysin and synaptoporin expression in the developing rat olfactory system
}

\author{
M. Bergmann ${ }^{\text {a }}$, Th. Schuster ${ }^{\text {a }}$, D. Grabs ${ }^{a}$, B. Marquèze-Pouey ${ }^{\text {b, } *, H . ~ B e t z ~}{ }^{c}$, H. Traurig ${ }^{d}$, \\ A. Mayerhofer ${ }^{\mathrm{e}}$ and M. Gratzl ${ }^{\mathrm{e}}$ \\ ${ }^{a}$ Institut für Anatomie, Charité, Humboldt-Universität zu Berlin, Berlin (Germany), ${ }^{b}$ ZMBH, Universität Heidelberg, Heidelberg (Germany), \\ c Abteilung für Neurochemie, Max-Planck-Institut für Himforschung, Frankfurt a.M. (Germany), 'Department of Anatomy and Neurobiology, \\ University of Kentucky, Lexington, $K Y$ (USA) and ' Abteilung Anatomie und Zellbiologie, Universität Ulm, Ulm (Germany)
}

(Accepted 16 February 1993)

Key words: Olfactory system; Synaptic vesicle; Development; Rat; Synaptophysin; Synaptoporin; Hybridization histochemistry; Immunocytochemistry

\begin{abstract}
The expressions of two closely related synaptic vesicle antigens synaptophysin and synaptoporin were examined in the olfactory system of the adult rat and during pre- and postnatal development. In the adult, immunocytochemistry showed that the continuously regenerating olfactory receptor neurons (primary neurons) produce both synaptophysin and synaptoporin which were localized in the cell bodies of the receptor neurons in the olfactory epithelium, their dendrites, axonal processes in the olfactory nerve and their terminals in the olfactory bulb giomeruli. Furthermore, ultrastructural analysis revealed synaptophysin- and synaptoporin-immunoreactivities associated with synaptic vesicles in most olfactory receptor axonal terminals impinging on dendrites of the mitral and tufted neurons (secondary neurons in the olfactory bulb circuitry) in the olfactory glomeruli. In like manner, tufted neurons, granule and periglomerular neurons (interneurons in the olfactory bulb circuitry) express both synaptophysin and synaptoporin. In contrast, mitral neurons expressed only the synaptophysin antigen which was likewise associated with mitral axonal terminals in their target the olfactory cortex. The patterns of synaptophysin and synaptoporin expressions in mitral neurons (synaptophysin only) and tufted neurons (synaptophysin and synaptoporin) were similar in prenatal, postnatal and adult rats as revealed by immunocytochemistry and in situ hybridization. However, the biosynthesis of synaptophysin and synaptoporin by granule and periglomerular neurons, olfactory bulb interneurons, occurred mainly postnatally.
\end{abstract}

\section{INTRODUCTION}

Significant progress has been made in the identification and characterization of membrane proteins which are common to synaptic vesicles ${ }^{19,42}$. These include members of a putative channel protein super-family, synaptophysin $(\mathrm{SY})^{4,20,50,51}$ and synaptoporin $(\mathrm{SO})^{21}$. SY and SO display a high degree of sequence identity ${ }^{21}$ and have been suggested to form gap junction-like channels during neurotransmitter release ${ }^{3,44}$. SY binds to the presynaptic plasma membrane protein physophilin and may thus participate in the docking of synaptic vesicles to their release sites ${ }^{43}$.

An analysis of SY and SO transcripts in the postnatal and adult rat central nervous system revealed spe- cific patterns of expression for these proteins in distinct brain areas ${ }^{29}$ suggesting that the synaptic vesicles of specific subgroups of neurons may be endowed with different membrane proteins. Recently striatal GABAergic neurons in the adult rat brain were shown to synthesize mainly SO, whereas SY is the major synaptic vesicle antigen of neurons projecting to the striatum ${ }^{33}$. Surprisingly, during prenatal development, striatal neurons express SY instead of SO, indicating that during ontogeny neurons can produce synaptic vesicles with different membrane compositions. Interestingly in the adult rat, the secondary neurons of the olfactory bulb exhibit highly characteristic distributions of SY and SO transcripts ${ }^{29}$. Specifically, both SY and SO mRNAs are found in tufted neurons whereas mi-

Correspondence: M. Gratzl, Abteilung Anatomic und Zellbiologie der Universität Ulm, 89069 Ulm, Germany. Fax: (49) (731) 502-3217.

* Present address: Faculté de Medicine-Nord, University of Marseille, F-13010 Marseille, France. 
tral neurons show an intense signal for $\mathrm{SY}$, but not for SO mRNA. However, the presence of SY and SO as well as their distribution patterns in the entire olfactory system and possible developmental changes were not examined. Because the neurochemical characteristics and the development of the olfactory bulb circuitry and its afferent and efferent projections are rather well-understood (see refs. 6, 14 for reviews), we have addressed this question and examined the expression of SY and SO in the olfactory system of the developing and the adult rat using in situ hybridization histochemistry and immunocytochemistry at the light microscopical and ultrastructural levels.

We found that (1) receptor (primary) neurons continuously produce $\mathrm{SY}$ and $\mathrm{SO}$ and transport these proteins to their terminals in the olfactory glomeruli. (2) Of the secondary olfactory neurons, the mitral neurons express only SY, which is transported to their endings in the olfactory cortex. In contrast, the tufted neurons, the other type of secondary olfactory neurons, express both SY and SO. (3) Differential expressions of the synaptic vesicle antigens $\mathrm{SY}$ and $\mathrm{SO}$ are characteristic properties of olfactory output neurons (mitral and tufted neurons) during prenatal, early postnatal development and in the adult. (4) Expression of SY and SO in olfactory interneurons (granule and periglomerular neurons) occurs mainly postnatally. (5) During synaptogenesis synaptic vesicle proteins accumulate in axonal terminals and SY and SO immunoreactivities disappear in nerve processes.

\section{MATERIALS AND METHODS}

\section{Animals}

Adult rats of both sexes and pregnant rats (Sprague-Dawley) were purchased from Charles River (Sulzfeld, FRG). The animals were anesthesized with $4 \%$ chloralhydrate $(1 \mathrm{ml} / 100 \mathrm{~g}$ b.wt.) prior to surgical procedures. Embryonic brains were obtained from pregnant rats on days 17 to 22 (E 17-22, day of insemination $=$ day 0$)$ and from newborn $(P$ 0) and young postnatal rats $(\mathrm{P} 8 / \mathrm{P} 15)$. Brains were removed and processed as described below.

\section{In situ hybridization histochemistry}

Cryostat sections of embryonic rat brains were mounted on poly-L-lysine-coated slides and fixed in $4 \%$ $(\mathrm{w} / \mathrm{v})$ paraformaldehyde in PBS. In situ hybridization was performed as previously described ${ }^{29}$. Briefly, antisense oligonucleotide probes (45 bp) ASy1, complementary to nucleotides 514-557 of the rat synaptophysin $\mathrm{cDNA}^{25}$, and ASo1 (complementary to nucleotides 1135-1180) and ASo2 (complementary to nu- cleotides 922-965) specific for rat synaptoporin tran scripts $^{21}$ were used in all experiments. ''robes were $3^{\prime}$ end-labeled to identical specific activities with $5^{\prime}$-[alpha- $\left.{ }^{35} \mathrm{~S}\right]$ dATP $(1,200 \mathrm{Ci} / \mathrm{mmol}$, NEN $)$ using terminal deoxynucleotidyl transferase (Gibco, BRL) at a $30: 1$ molar ratio of dATP: oligonucleotide. Control hybridizations were performed in the presence of a 50 fold excess of unlabelled oligonucleotide. Sections were dipped in autoradiography emulsion, exposed, developed and stained with $0.1 \%(\mathrm{w} / \mathrm{v})$ thionin.

\section{Immunocytochemistry}

For light microscopic immunocytochemistry, brains were immersed in Bouin's fixative for $12 \mathrm{hrs}$ and embedded in paraffin. Sections $(6 \mu \mathrm{m})$ were cut and mounted on gelatin-coated glass slides. For immunohistochemical detection of SY and SO, polyclonal rabbit antisera directed against rat synaptophysin ${ }^{20}$ (kindly provided by R. Jahn, New Haven) or synaptoporin ${ }^{21}$ were used. Preliminary studies had shown that antibody dilutions of $1: 1,000$ (SY) and 1:200 (SO) resulted in highly specific labeling signals, therefore these dilutions were used in all experiments reported here. Details of the immunocytochemical procedures have been described previously $2,23,33$. Antigen/antibody complexes were visualized by the avidin-biotin-peroxidase complex (ABC) technique ${ }^{17}$. Controls incubated with $2 \%$ goat serum in PBS or with normal rabbit serum $(1: 1,000)$ showed no immunoreactivities.

Specimens for electron microscopy were obtained from anesthesized, pregnant or non-pregnant rats as follows. Fetuses were removed by Cesarean section and perfused transcardially for 5-6 min with $2 \%$ paraformaldehyde, $0.5 \%$ glutaraldehyde, $1 \%$ acrolein, $2,5 \%$ dimethyl sulfoxide $(\mathrm{v} / \mathrm{v}), 9 \mathrm{mM} \mathrm{CaCl}_{2}$ in $0.1 \mathrm{M}$ cacodylate buffer, $\mathrm{pH}$ 7.4.; adult rats were perfused through the ascending aorta with the same fixative for 15 min. Subsequently, brains were removed, postfixed in the same fixative at $4^{\circ} \mathrm{C}$ for $3-4 \mathrm{~h}$, and placed in PBS overnight. Sections $(30 \mu \mathrm{m})$ were cut on a vibratome (Oxford Instruments) and processed for preembedding staining employing the $\mathrm{ABC}$ technique ${ }^{17}$. After treatment in $5 \%$ goat serum the sections were incubated for $12 \mathrm{~h}$ at room temperature and for $24 \mathrm{~h}$ at $4^{\circ} \mathrm{C}$ with anti-SY $(1: 1,000)$ or anti-SO $(1: 200)$, respectively. Biotinylated goat anti-rabbit IgG $(1: 200$ dilution, $1 \mathrm{~h})$ and avidin-biotin-peroxidase complex $(1: 250$ dilution, 2 h, Camon, Wiesbaden, Germany) were used in the second and third steps of immunostaining. All incubations were carried out at room temperature under gentle shaking. The peroxidase substrate consisted of $0.05 \%, 3,3^{\prime}$-diaminobenzidine-tetrahydrochloride (Aldrich, Steinheim, Germany). The sections of the 

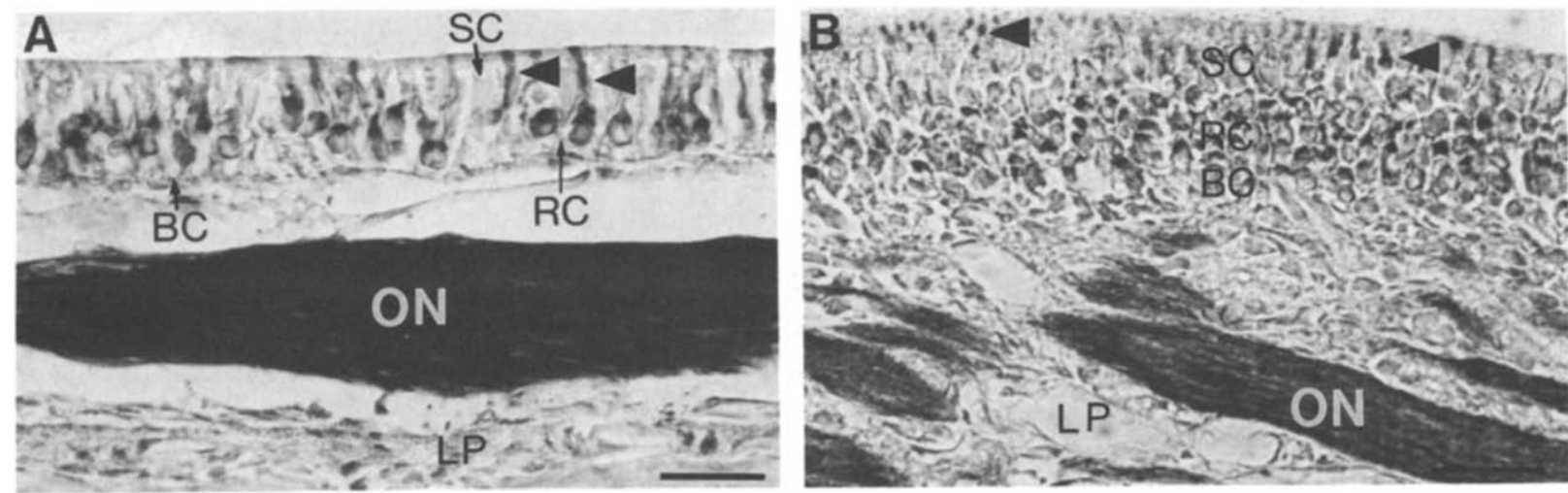

Fig. 1. Immunocytochemical detection of SY and SO in the adult olfactory mucosa. The receptor neurons (RC) showed a perinuclear cap-like arrangement of perikaryal SY (A) and SO (B) immunostaining which also extended into the apical dendrites (arrowheads) and into the axonal

bundles of the olfactory nerve $(\mathrm{ON})$ within the lamina propria (LP). Basal $(\mathrm{BC})$ and supporting cells $(\mathrm{SC})$ were unstained. Bars $=25 \mu \mathrm{m}$.

olfactory bulb were postfixed in $1 \% \mathrm{OsO}_{4}$ in $0.1 \mathrm{M}$ phosphate buffer, $\mathrm{pH} 7.2$, for $45 \mathrm{~min}$, rapidly dehydrated and embedded in Epon 812 (Fluka, Neu-Ulm, Germany). For polymerization, sections were placed between coverslips and slides precoated with dimethyldichlorosilane. Ultrathin sections were viewed unstained or poststained with lead citrate and uranyl acetate. Controls were carried out as described above.

\section{RESULTS}

Distribution of SY and SO in the adult olfactory system

In the adult SY and SO antigens were found in the primary olfactory neurons of the olfactory mucosa (Fig. 1). SY immunoreactivity was more intense compared to SO (Fig. 1A and B). Characteristically, the nuclei of olfactory receptor neurons in the basal third of the epithelium were surrounded by a prominently-immunoreactive cytoplasm (Fig. 1A and B). In addition, the apical dendrites of olfactory receptor neurons and their axons in the olfactory nerve within the lamina propria exhibited intense immunostaining (Fig. 1A and B). In contrast, supporting and basal cells of the olfac- tory epithelium were immunonegative for both synaptic vesicle antigens (Fig. 1A and B).

In the olfactory bulb both SY and SO antigens were highly concentrated in the olfactory glomeruli (Fig. 2A and $\mathrm{B}$ ). Prominent immunostaining for SY and SO was also observed in the neuropil of the external plexiform layer, while the granule cell layer was less intensely stained; in contrast, the perikarya of the olfactory bulb neurons were unlabeled (Fig. 2A and B).

Ultrastructural observations revealed numerous SY and SO immunostained presynaptic endings in the olfactory glomeruli (Fig. 3A and B); but, unstained endings were also detected (Fig. 3A and B). All synaptic vesicles exhibited similar degrees of immunolabeling within a particular presynaptic bouton, but, unstained, faintly stained or intensely stained terminals could often be observed within the same glomerulus (Fig. 3C). A similar distribution of SY and SO immunoreactivity was observed in terminals of the external plexiform layer (not shown).

SY immunoreactivity was prominent in terminals in the piriform cortex - the mitral neuron target. In particular, the superficial half of the (superficial) plexi-
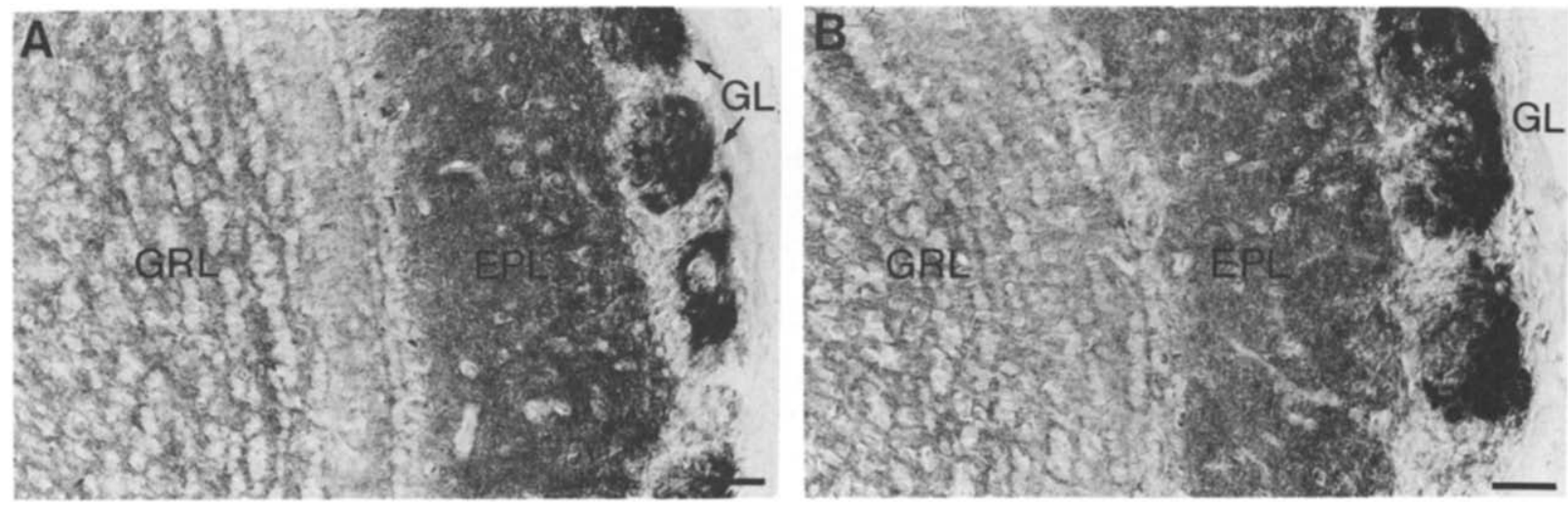

Fig. 2. Immunocytochemical detection of SY and SO in the adult olfactory bulb. SY (A) and SO (B) immunoreactivities were highly concentrated in the olfactory glomeruli (GL). SY and SO immunostaining was prominent in the neuropil of the external plexiform (EPL), less intense in granule neuron layer (GRL) and absent from perikarya of the bulb cells. Bars $=50 \mu \mathrm{m}$. 

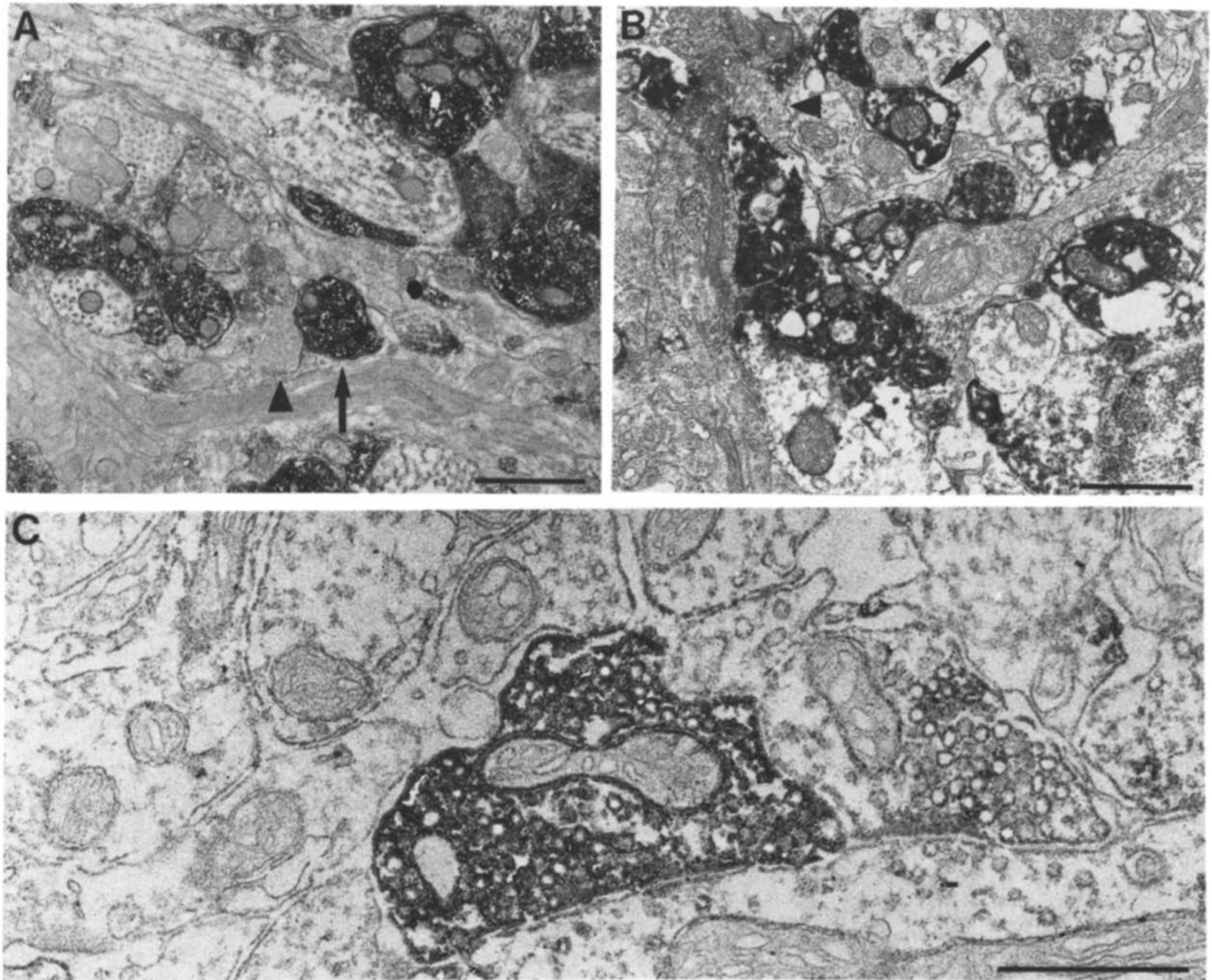

Fig. 3. Ultrastructural localization of SY and SO immunoreactivity in the adult olfactory bulb. A,B: numerous SY (A) and SO (B) immunostained presynaptic endings (arrows) were found in the olfactory glomeruli. Unstained endings (arrowheads) were also detected. C: two examples of SY immunoreactive boutons displaying different degrees of labeling. Bars in $\mathrm{A}$ and $\mathrm{B}=1 \mu \mathrm{m}$ and in $\mathrm{C}=0,5 \mu \mathrm{m}$.

form cell layer (commonly referred to as layer 1a) of the piriform cortex exhibited intense immunostaining (Fig. 4A), but failed to display SO immunoreactivity (data not shown). Finally, SY immunostaining was not detected in the perikarya of the pyramidal cells and in the adult lateral olfactory tract (Fig. 4A).
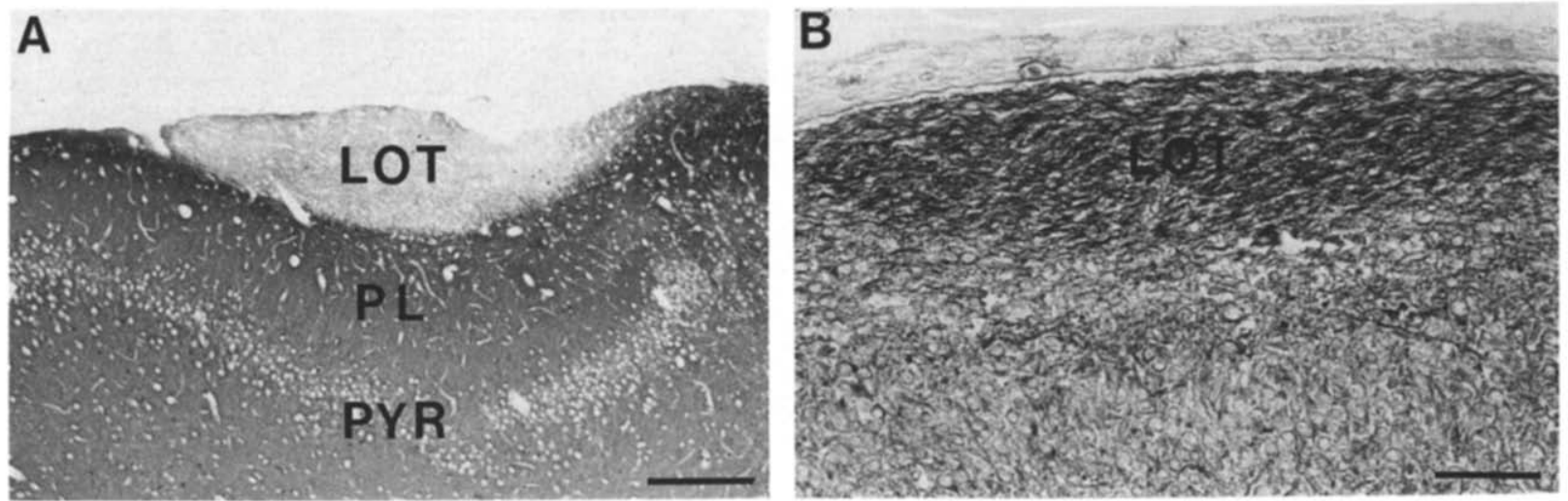

Fig. 4. Immunocytochemical detection of SY in the adult lateral olfactory tract and at E21. The lateral olfactory tract (LOT) was unstained in the adult brain (A), while intense SY immunostaining is a characteristic feature of the LOT during late embryonic development (B, E21). Note the prominent SY immunoreactivity in the plexiform layer (PL) of the adult piriform cortex, while the perikarya of pyramidal cells (PYR) were unstained. Vibratome section (A). Bars in $A=200 \mu \mathrm{m}$ and in $B=50 \mu \mathrm{m}$. 
Localization of $S Y$ and $S O$ in the developing olfactory bulb

The postnatal expression of SY and SO genes has been analyzed in many regions of the central nervous system using in situ hybridization ${ }^{29}$. The present observations using hybridizations with specific oligonucleotide probes revealed that the patterns of SY and SO expressions in developing olfactory bulb did not change markedly between E17 and birth. For example, olfactory bulb exhibited robust expressions of SY mRNA in the mitral neuron layer on embryonic day 19 (E19) (Figs. 5A and 6A). Also, some tufted neurons of the external plexiform layer showed an intense signal for SY (Fig. 6A), but the olfactory neuroepithelium, which develops into the granule cell layer, displayed only moderate levels of SY transcripts (Fig. 5A). In contrast to the prominent expressions of SY, signals for SO mRNA were low in the olfactory bulb at E19 (Fig. 5B). Specifically, the SO probe failed to produce detectable hybridization signals in the mitral neuron layer, and only moderate levels of SO mRNA were evident in the olfactory neuroepithelium and the external plexiform layer (Fig. 5B and 6B). The SO signals in the external plexiform layer were localized to tufted neurons (Fig. 6B).

Immunocytochemical observations on the developing olfactory bulb were consistent with the distributions of SY and SO transcripts described above. Thus, intense, perikaryal SY immunolabeling was observed in the mitral neurons between E17 and birth. The immunoreactivity was arranged in a cap-like, perinuclear distribution as shown for E21 (Fig. 7). In addition, prominent SY immunostaining was found in neuron processes - most probably originating from output neurons (Fig. 7A). At E20/21, the earliest evidence of SY immunoreactivity became detectable in olfactory glomeruli (Fig. 7A). Foci of SY immunoreactivity within the olfactory glomeruli, observed by light microscopy, represented vesicle-filled, heavily stained presynaptic profiles as revealed by electron microscopy (Fig. 8A and $B$ ). Moreover, these profiles were apposed to unstained dendrites (Figs. 8A and B), which rarely exhibited postsynaptic specializations (Fig. 8B). Prominent SY-immunoreactive nerve processes were observed in the lateral olfactory tract from E17 until birth (see examples in Figs. 4B and 7A).

The expressions of SY and SO mRNA transcripts in postnatal olfactory bulb mitral and tufted neurons were similar to expressions of these transcripts in the prenatal period (Figs. 5 and 6 ). Two notable exceptions were the prominent signals for SY and SO associated with periglomerular neurons after birth (for SO see Fig. 9A) and the presence of high levels of SO transcripts in granule neurons of the olfactory bulb between postnatal day P8 (see Fig. 9A) and P15. Immunocytochemical data revealed punctuate staining for $\mathrm{SO}^{\circ}$ in the olfactory glomeruli and in the external plexiform layer at $\mathbf{P} 8$ (data not shown). Also, intense immunoreactivities for SO were observed in the perikarya and dendrites of granule neurons (Fig. 9B).

\section{DISCUSSION}

Analysis of SY and SO transcripts in neurons in the olfactory bulb circuitry reveal distinct patterns of expression of these synaptic vesicle proteins. Our data demonstrate that the primary olfactory neurons and the olfactory bulb interneurons (granule and periglo-
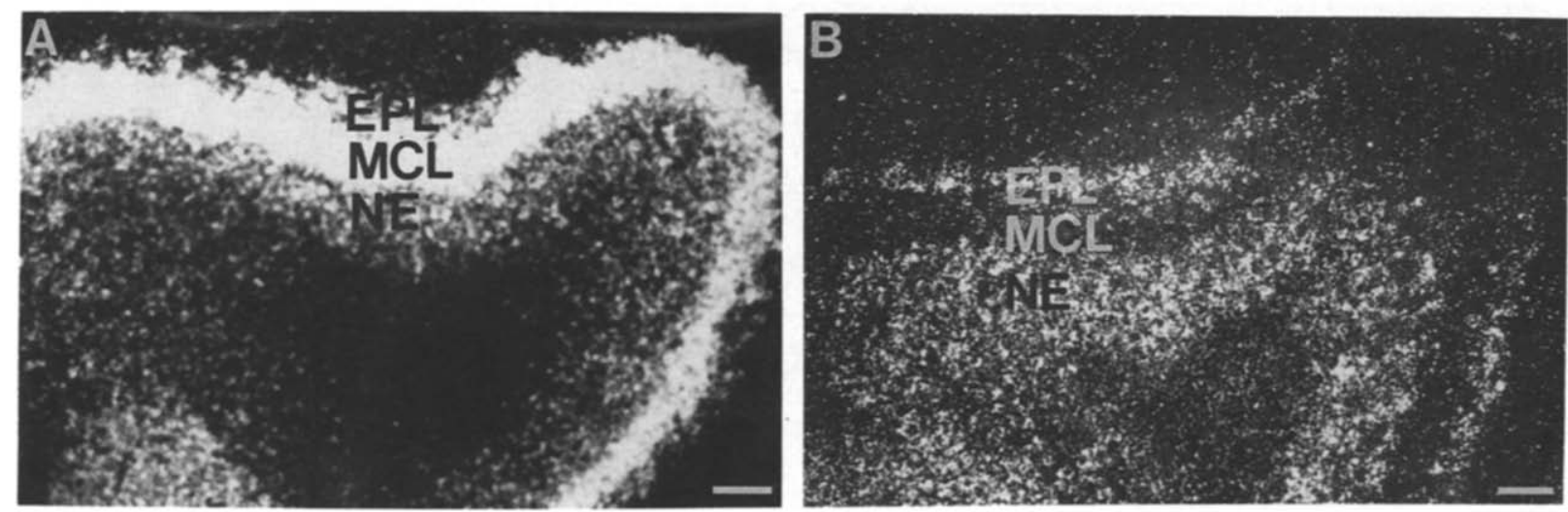

Fig. 5. Visualization of SY and SO transcripts in the olfactory bulb at E19. In situ hybridization histochemistry revealed an intense signal for SY in the mitral neuron layer (MCL) and the external plexiform layer (EPL). The neuroepithelium (NE) displayed only moderate levels of SY transcripts (A). For SO moderate levels of transcripts were observed in the neuroepithelium (NE) and in the external plexiform layer (EPL). Note the absence of SO signals in the mitral cell layer (B). Dark field. Bars $=100 \mu \mathrm{m}$. 

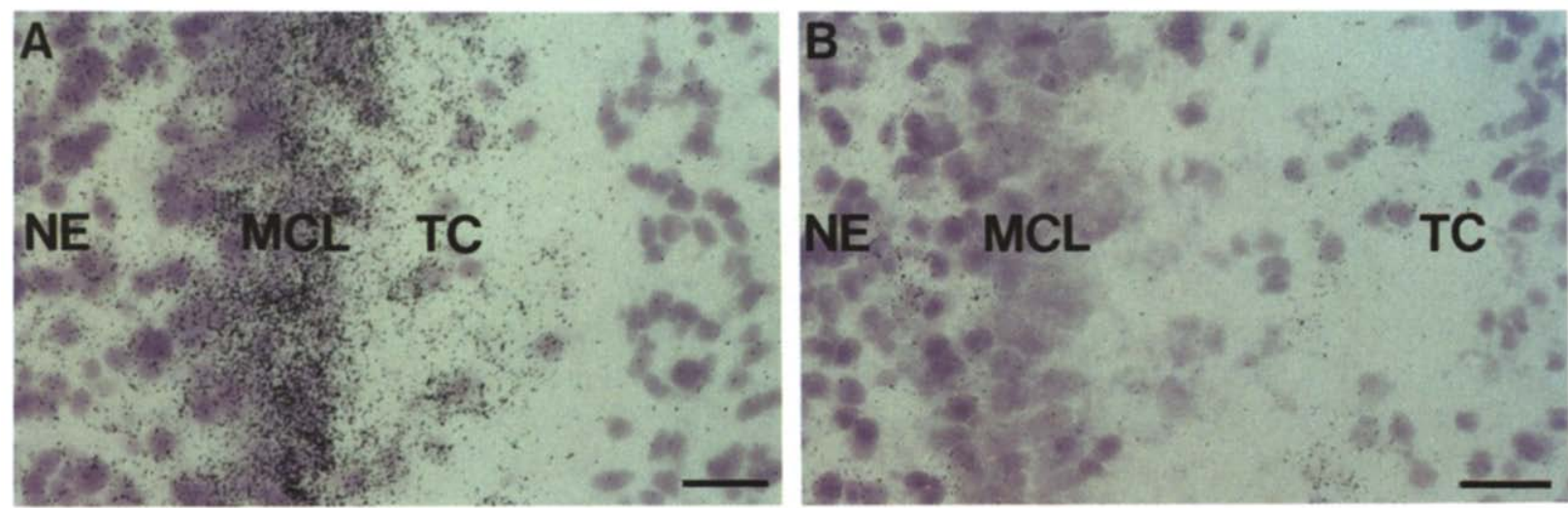

Fig. 6. SY and SO mRNA transcripts in the mitral neuron layer and in the external plexiform layer at E19. At higher magnification in addition to intense SY signals in the mitral neuron layer (MCL), tufted neurons (TC) and neuroepithelial cells (NE) just beneath the MCL also showed signals (A). Signals for SO transcripts (B) were found in some neuroepithelial (NE) and tufted neurons (TC), but not in mitral neurons (MCL). Bright field. Bars $=30 \mu \mathrm{m}$.
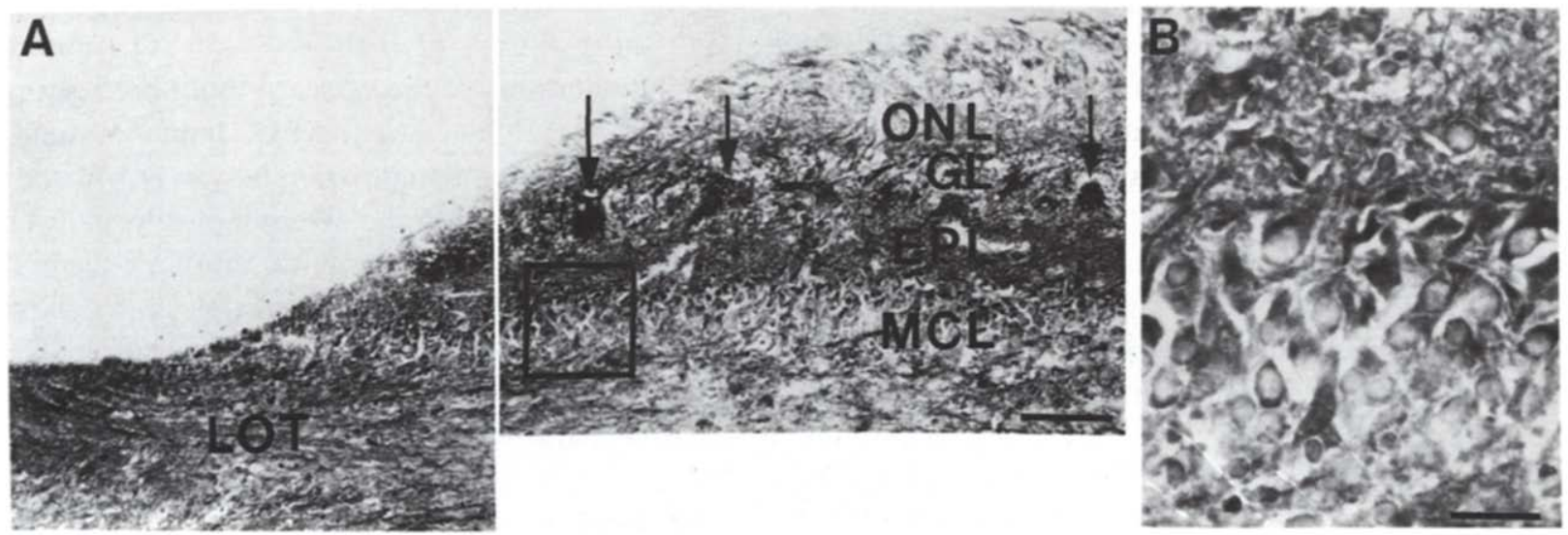

Fig. 7. Immunocytochemical detection of SY in the olfactory bulb and in the forming lateral olfactory tract at E21. SY immunoreactivity (arrows) in the glomerular layer (GL) was observed at E20/21 (see also Fig. 8). Note immunoreactivity in the olfactory nerve layer (ONL), external plexiform layer (EPL) and in the perikarya of mitral neurons (MCL). In addition, thick SY immunoreactive nerve fiber bundles were conspicuous in the forming lateral olfactory tract (LOT) (A). The intense perinuclear SY immunolabeling of the mitral neurons is shown at higher magnification (B). Bars in $A=100 \mu \mathrm{m}$ and in $B=25 \mu \mathrm{m}$.
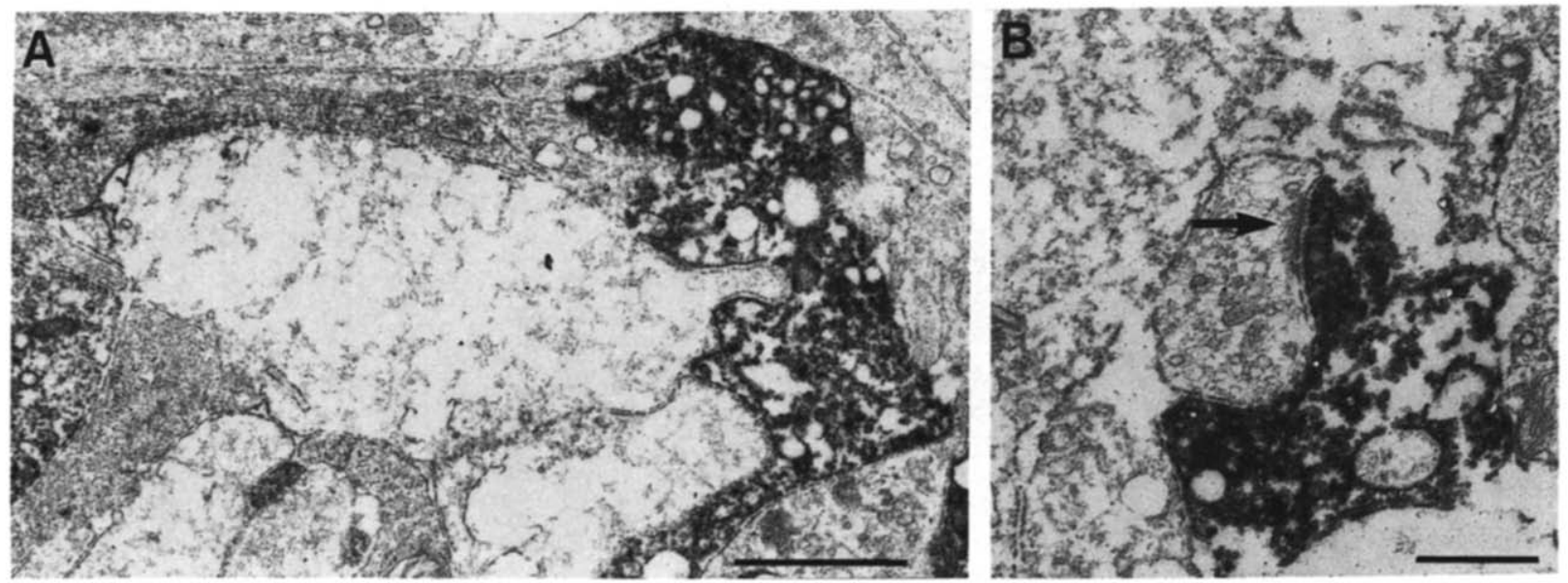

Fig. 8. Ultrastructural localization of SY immunoreactivity in the olfactory glomeruli at E20. Numerous vesicle-filled presynaptic profiles, heavily stained with peroxidase reaction product, were apposed to unstained dendrites (A). Postsynaptic membrane specialization (arrow) was rarely found (B). Bars in $A=1 \mu \mathrm{m}$ and in $B=0.5 \mu \mathrm{m}$. 

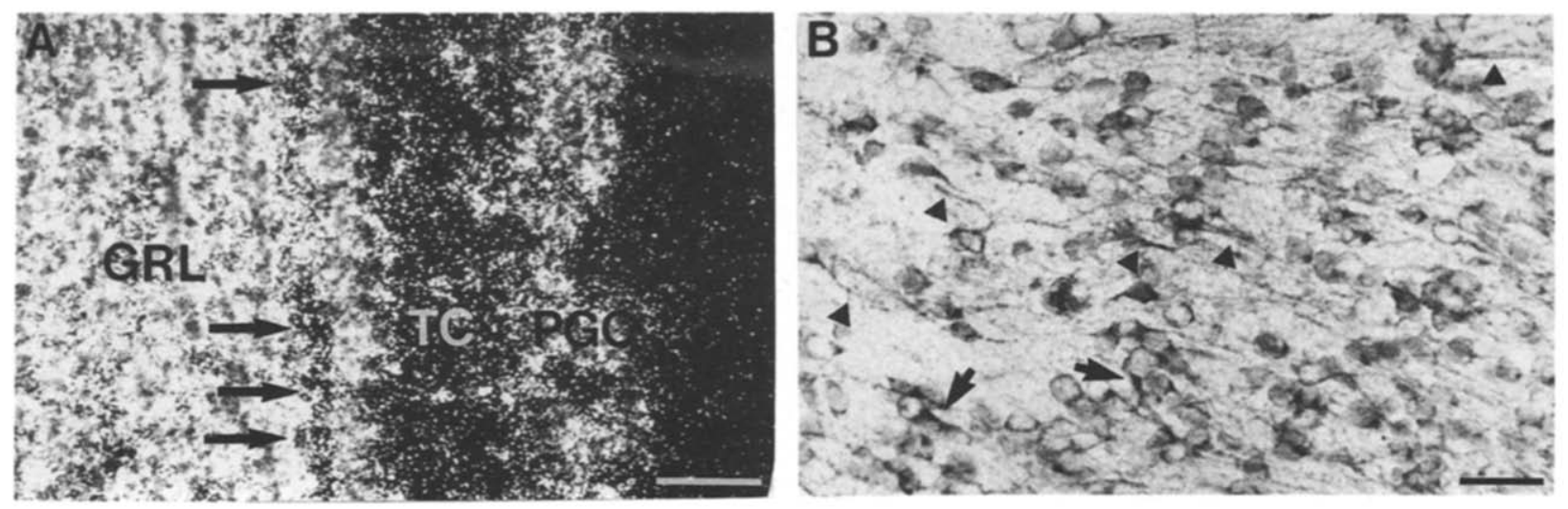

Fig. 9. Visualization of SO in the olfactory bulb at P8. High concentrations of SO transcripts were evident in granule neurons (GRL). Signals for SO were also exhibited in tufted (TC) and periglomerular neurons (PGC). Note the absence of signals in mitral neurons (arrows) (A). SO immunoreactivity was detected in the perikarya (arrows) and dendrites (triangle) of granule neurons (B). Bars in $\mathrm{A}=100 \mu \mathrm{m}$ and in $\mathrm{B}=30 \mu \mathrm{m}$.

merular neurons) express both SY and SO antigens in the adult. In contrast, these synaptic vesicle proteins are differentially expressed in the secondary neurons, the mitral and tufted neurons. Specifically, tufted neurons express both SY and SO, whereas mitral neurons contain only SY. These differential distributions of synaptic vesicle proteins imply different compositions of the tufted and mitral axonal terminals in their targets-the olfactory cortex. Moreover, similar distributions of these synaptic vesicle proteins are evident in the olfactory circuit neurons during development. These differences in synaptic vesicle antigen expressions may reflect functionally important differences in the release of neurotransmitters or neurotrophic factors.

\section{Ontogeny of $S Y$ and $S O$ expression in the olfactory system}

The sequence of neuronal birthdays of the 4 main neurons of the rat olfactory bulb circuit are known. Thus, the output neurons, mitral and tufted neurons, originate in the late embryonic period, whereas the interneurons, periglomerular and granule neurons, appear mainly during the first 2 weeks after birth ${ }^{1}$. Our data reveal high levels of SY mRNA and SY protein in mitral and tufted neurons between E17 and P15 while SO expression was observed predominantly in granule neurons only after birth. Thus, we conclude that the onset of synaptic vesicle antigen expression correlates with the neuronal birthdays.

The earliest axodendritic synapses in the olfactory bulb were reported to form just beneath the olfactory nerve layer on $E 18^{9,12}$. Our ultrastructural data suggest that most synaptic vesicle-containing axonal terminals in the developing olfactory glomeruli may not be functional because few postsynaptic specializations develop before E20. Nerve terminals containing synaptic vesi- cles prior to forming functional synaptic contacts have also been reported in developing or cultured hippocampal neurons ${ }^{10,30,47}$ and in developing spinal cord ${ }^{2}$ and striatum ${ }^{33}$. The formation of postsynaptic elements at sites of contact between synaptic vesicle containing terminals and postsynaptic neurons in the olfactory glomeruli after E20 appears to be tightly linked with the development of specific transmitter systems in the olfactory bulb (see refs. 6, 14, 28 for reviews) and the onset of olfactory function ${ }^{12,34,39}$.

In summary, our data show that synaptic vesicle proteins are synthesized and transported to axons in immature olfactory bulb neurons during axon outgrowth. After formation of cell contacts and redistribution of synaptic vesicles to developing axonal terminals during synaptogenesis, synaptic vesicles are no longer detected in the fibers. Also the secondary neuron axons projecting to the olfactory cortex and which form the lateral olfactory tract around E1 $7^{27,36,37}$, are intensely immunoreactive for SY. Subsequently, the protein gradually disappears from the nerve fibers (compare Fig. 4A and B). Adult mitral neurons rapidly transport $S Y$ to their axonal terminals in their target, the piriform cortex, but SY immunoreactivity in mitral neuron processes is virtual absent.

The postnatal appearance of SY and SO in the interneurons (periglomerular neurons) of the olfactory bulb correlates with the onset of tyrosine hydroxylase (TH) expression, the rate-limiting enzyme in the biosynthesis of catecholamines ${ }^{15,31,38,40,41}$. Furthermore, robust expressions of SY, and particularly of SO, in the granule neurons suggests that expressions of these antigens parallel the development of GABAergic systems in the deeper layers of the olfactory bulb during the postnatal period ${ }^{22}$. The presence of the neuronal growth-associated protein B50/GAP43 in the olfactory bulb $^{48}$ and the transient overshoot of spine and synapse 
formation by granule neurons ${ }^{35}$ also suggests that synaptogenesis and synaptic plasticity occur after birth in the olfactory interneurons.

Continuous expression of $S Y$ and $S O$ in the primary (receptor) neurons of the olfactory system

The most unique feature of the olfactory mucosa is the life-long turnover of the receptor neurons ${ }^{5,8,13,16}$. Our present data demonstrate that the olfactory receptor neurons express both synaptic antigens, SY and SO, during their functional regeneration, elaboration of new dendrites, axons and synaptic contacts with their targets-the olfactory glomeruli. The pattern of synaptic antigen expression in the receptor neurons closely resembles that found in other brain areas during embryonic development; specifically, a cap-like distribution of perinuclear immunoreactivity in the perikarya and intense immunolabeling of growing axons are evident. Perikaryal immunostaining for synaptic vesicle proteins and high levels of their mRNAs are also concomitant with neuron process outgrowth in the developing spinal cord $^{2}$, striatum ${ }^{33}$, olfactory bulb (this study) and hippocampus (Grabs et al., unpublished).

\section{Differential expression of $S Y$ and $S O$ in the secondary} neuron in the adult olfactory system

Our results reveal that expressions of the synaptic vesicle proteins SY and SO differ in the secondary olfactory neurons. Thus, mitral neurons, one type of output neuron, express only SY; in contrast, tufted neurons, the other type of output neuron express both SY and SO (ref. 29 and this study). Also in other brain areas similar differential expressions of the synaptic vesicle antigens SY and SO have been observed, i.e. CA1 $/ 2$ pyramidal neurons of the hippocampus ${ }^{29}$ (Grabs et al., unpublished), striatal neurons ${ }^{33}$ and most strikingly in all neurons of the cerebellum ${ }^{29}$. Other isoforms of synaptic vesicle proteins, synaptobrevin (VAMP-1 and VAMP-2) and synaptotagmin, have different, although partially overlapping, patterns of expression $^{7,11,46,49}$. Taken together, it is evident that functionally-related neurons may elaborate synaptic vesicles which differ in their membrane proteins.

Earlier ultrastructural studies suggested an ubiquitous occurrence of $S Y$ in nerve terminals ${ }^{26,32,45,47,50}$. However, the ultrastructural analysis of $S Y$ and $S O$ in the present study indicates a patterned distribution of these synaptic vesicle membrane proteins. Individual nerve terminals exhibit differences in SY and SO staining intensities suggesting variations in the stoichiometric ratio of SY and SO in different nerve terminals. It should be added that besides immunolabeled endings, unstained endings were also detected. It is not known, whether these unstained terminals contain other synaptic vesicle antigens like synaptobrevins ${ }^{7,46}$, synaptotagmins ${ }^{49}$ or other newly detected members of the synaptophysin/synaptoporin family ${ }^{4,51}$. Further immunolabeling studies localizing these and other synaptic vesicle membrane proteins at subcellular levels are needed to elucidate more precisely the synaptic vesicle membrane composition of different neurons.

Comparison of the distribution of $S Y$ and $S O$ as markers for small synaptic vesicles to Chromogranin A (CGA), a marker for large dense-core vesicles

Release of classical neurotransmitters (such as acetylcholine, amino acids) is thought to occur from small synaptic vesicles, whereas neuropeptides are released from dense-core vesicles. The chromogranins/ secretogranins can serve as markers for the latter type of vesicle ${ }^{18}$. Furthermore Chromogranin A (CGA) is a prominent component of the olfactory bulb $b^{23,24}$ and immunocytochemical data $^{23}$ revealed expression of CGA in the axonal endings of the secondary olfactory neurons, but not in the olfactory glomeruli. These data imply that CGA is biosynthesized in the perikarya of the mitral and tufted neurons and is specifically transported to their axonal terminals in the olfactory cortex but not to their primary dendrites ${ }^{23}$. As noted above, both SY and SO were detected in the primary olfactory neurons and evidence implies their transport to the olfactory glomeruli (this study). In contrast, the secondary olfactory neurons differ from one another ${ }^{29}$ (and this study) and from the primary olfactory neurons in that mitral neurons express the vesicle proteins CGA and SY but not SO; on the other hand, tufted neurons express CGA, SY and SO. These observations indicate that components of dense-core vesicles and synaptic vesicles are differentially distributed in the olfactory system neurons which may reflect specific functional roles, neurotransmitter and/or neuropeptide contents of the different secretory vesicles of distinct olfactory neuron types.

Acknowledgements. The authors thank Mrs. G. Duwe, H. Heilmann, A. Lehmann, E. Roeseler, I. Urban and D. Wachenschwanz for expert technical assistence, and Mrs. E. Kruschinski for typing this manuscript. This study was supported by Deutsche Forschungsgemeinschaft (Be 1330, Gr 681, Ma 1080, Leibniz-Programm and SFB 317), grants from the Charité (Projekt 053 to M.B. and Projekt 050 to Th.Sch.), DAAD (fellowship to H.T.), EMBO (long-term fellowship to B.M.-P.) and Fonds der Chemischen Industrie.

\section{REFERENCES}

1 Bayer, S.A., 3H-Thymidine-radiographic studies of neurogenesis in the rat olfactory bulb, Exp.Brain Res., 50 (1983) 329-340

2 Bergmann, M., Lahr, G., Mayerhofer, A. and Gratz1, M., Expression of synaptophysin during the prenatal development of the rat 
spinal cord: correlation with basic differentiation processes of neurons, Neuroscience, 42 (1991) 569-582

3 Betz, H., Homology and analogy in transmembrane channel design: lessons from synaptic membrane proteins, Biochemistry, 29 (1990) 3591-3599

4 Bixby, J.L., Identification of an alternatively spliced avian member of the synaptophysin gene family, Mol. Brain Res., 13 (1992) 339-348

5 Breipohl, W., Mackay-Sim, A., Grandt, D., Rehn, B. and Darrelmann, $C$., Neurogenesis in the vertebrate main olfactory epithelium. In W. Breipohl (Ed.), Ontogeny of Olfaction, Springer, Berlin, 1986, 21-33.

6 Brunjes, P.C. and Frazier, L.L., Maturation and plasticity in the olfactory system of vertebrates, Brain Res. Rev, 11 (1986) 1-45

7 Elferink, L.A., Trimble, W.S. and Scheller, R.H., Two vesicle-associated membrane protein genes are differentially expressed in the rat central nervous system, J. Cell Biol., 19 (1989) 11061-11064

8 Farbman, A.I., Olfactory neurogenesis: genetic or environmental controls? Trends Neurosci, 13 (1990) 362-365

9 Farbman, A.I. and Squinto, L.M., Early development of olfactory receptor cell axons, Dev. Brain. Res., 19 (1985) 205-213

10 Fletcher, T.L., Cameron, P., De Camilli, P. and Banker, G., The distribution of synapsin I and synaptophysin in hippocampal neurons developing in culture, $J$. Neurosci., 11 (1991) 1617-1626

11 Geppert, M., Archer I, B.T. and Südhof, T.C., Synaptotagmin II. A novel differentially distributed form of synaptotagmin, J. Biol. Chem., 266 (1991) 13548-13552

12 Gesteland, R.C., Yancey, R.A. and Farbman, A.I., Development of olfactory receptor neuron selectivity in the rat fetus, Neuroscience, 7 (1982) 3127-3136

13 Graziadei, P.P.C. and Monti Graziadei, G.A., Neurogenesis and neuron regeneration in the olfactory system of mammals $\mathrm{I}$. Morphological aspects of differentiation and structural organization of the olfactory sensory neurons, J. Neurocytol., 8 (1979) 1-18

14 Halász, N., The Vertebrate Olfactory System. Chemical Neuroanatomy, Function and Development, Akadémiai Kiadó, Budapest, 1990 .

15 Halász, N. and Shepherd, G.M., Neurochemistry of the vertebrate olfactory bulb, Neuroscience, 10 (1983) 579-619

16 Hinds, J.W. and McNelly, N.A., Aging in the rat olfactory system correlation of changes in the olfactory epithelium and olfactory bulb, J. Comp. Neurol., 203 (1981) 441-453

17 Hsu, S.M., Raine, L. and Fanger, H., Use of avidin-biotin-peroxidase complex $(\mathrm{ABC})$ in immunoperoxidase techniques: a comparison between $\mathrm{ABC}$ and unlabeled antibody (PAP) procedures, J. Histochem. Cytochem., 29 (1981) 577-580

18 Huttner, W.B., Gerdes, H.-H. and Rosa, P., Chromogranins/ secretogranins-widespread constituents of the secretory granule matrix in endocrine cells and neurons. In M. Gratzl and K. Langley (Eds.), Markers for Neural and Endocrine Cells. Molecular and Cell Biology, Diagnostic Applications, VCH-Verlagsgesel1schaft, Weinheim, 1991, pp. 93-131.

$19 \mathrm{Jahn}, \mathrm{R}$. and De Camilli, P., Membrane proteins of synaptic vesicles: markers for neurons and neuroendocrine cells; tool for the study of neurosecretion. In M. Gratzl and K. Langley (Eds.), Markers for Neural and Endocrine Cells. Molecular and Cell Biology, Diagnostic Applications, VCH-Verlagsgesellschaft, Weinheim, 1991, pp. 25-92.

20 Jahn, R., Schiebler, W., Ouimet, C. and Greengard, P., A 38,000 -dalton membrane protein (p38) present in synaptic vesicles, Proc. Natl. Acad. Sci. USA, 82 (1985) 4137-4141

21 Knaus, P., Marquèze-Pouey, B., Scherer, H. and Betz, H., Synaptoporin, a novel putative channel protein of synaptic vesicles, Neuron, 5 (1990) 453-462

22 Kosaka, K., Hama, K., Nagatsu, I., Wu, J.-Y., Ottersen, O.P., Storm-Mathisen, J. and Kosaka, T., Postnatal development of neurons containing both catecholaminergic and GABAergic traits in the rat main olfactory bulb, Brain Res., 403 (1987) 355-360

23 Lahr, G., Heiss, C., Mayerhofer, A., Schilling, K., Parmer, R.J., O'Connor, D.T, and Gratzl, M., Chromogranin A in the olfactory system of the rat, Neuroscience, 39 (1990) 605-611

24 Lahr, G., Mayerhofer, A., Bergmann, M., Takiyyuddin, M.A. and
Gratzl, M., Chromogranin A in neurons of the rat cerebellum and spinal cord: quantification and sites of expression, J. Histochem. Cytochem., 40 (1992) 993-999

25 Leube, R.E., Kaiser, P., Seiter, A., Zimbelmann, R., Franke, W.W., Rehm, H., Knaus, P., Prior, H., Betz, H., Reinke, H., Beyreuthe-, K. and Wiedenmann, B., Synaptophysin: molecular organization and mRNA expression as determined from cloned cDNA, EMBO J., 6 (1987) 3261-3268

26 Mandell, J.W., Townes-Anderson, E., Czernik, A.J., Cameron, R., Greengard, P. and De Camilli, P., Synapsins in the vertebrate retina: absence from ribbon synapses and heterogeneous distribution among conventional synapses, Neuron, 5 (1990) 19-33

27 Marchand, R. and Bélanger, M.-C., Ontogenesis of the axonal circuitry associated with the olfactory system of the rat embryo, Neurosci. Lett., 129 (1991) 285-290

28 Margolis, F.L., Kawano, T. and Grillo, M., Ontogeny of carnosine, olfactory marker protein and neurotransmitter emzymes in olfactory bulb and olfactory mucosa of the rat. In W. Breipohl (Ed.), Ontogeny of Olfaction, Springer, Berlin, 1986, pp. 107-116.

29 Marquèze-Pouey, B., Wisden, W., Malosio, M.L. and Betz, H., Differential expression of synaptophysin and synaptoporin. $\mathrm{mR}$ NAs in the postnatal rat central nervous system, $J$. Neurosci., 11 (1991) 3388-3397

30 Matteoli, M., Takei, K., Perin, M.S., Südhof, T.C. and De Camilli, $P$., Exo-endocytotic recycling of synaptic vesicles in developing processes of cultured hippocampal neurons, J. Cell Biol., 117 (1992) 849-861

31 McLean, J.H. and Shipley, M.T., Postmitotic, postmigrational expression of tyrosine hydroxylase in olfactory bulb dopaminergic neurons, $J$. Neurosci., 8 (1988) 3658-3669

32 Navone, F., Jahn, R., Di Gioia, G., Stukenbrok, H., Greengard P. and De Camilli, P., Protein p38: An integral membrane protein specific for small vesicles of neurons and neuroendocrine cells, J. Cell Biol., 103 (1986) 2511-2527

33 Ovtscharoff, W., Bergmann, M., Marquèze-Pouey, B., Knaus, P., Betz, H., Grabs, D., Reisert, I. and Gratzl, M., Ontogeny of synaptophysin and synaptoporin expression in the central nervous system: differential expression in striatal neurons and their afferents during development, Dei. Brain. Res., 72 (1993) 219-225.

34 Pedersen, P.E., Stewart, W.B., Greer, C.A. and Shepherd, G.M. Evidence for olfactory function in utero, Science, 221 (1983) $478-480$

35 Rehn, B., Breipohl, W., Mendoza, A.S. and Apfelbach, R., Changes in granule cells of the ferret olfactory bulb associated with imprinting on prey odours, Brain Res., 373 (1986) 114-125

36 Schwob, J.E. and Price, J.L., The cortical projection of the olfactory bulb: development in fetal and neonatal rats correlated with quantitative variations in adult rats, Brain Res., 151 (1978) 369-374

37 Schwob, J.E. and Price, J.L., The development of axonal connections in the central olfactory system of rats, J. Comp. Neurol., 223 (1984) 177-202

38 Shipley, M.T., Sieloff, E.G., Lazoff, M. and McLean, J., Developmental expression of transmitter phenotype in brain dopaminergic neurons, Assoc. Chemorecept. Sci., VII (1985) 166

39 Smotherman, W.P. and Robinson, S.R., The rat fetus in its environment: behavioral adjustments to novel, familiar, aversive and conditioned stimuli presented in utero, Behat. Neurosci. 99 (1985) 521-530

40 Specht, L.A., Pickel, V.M., Joh, T.H. and Reis, D.J., Lightmicroscopic immunocytochemical localization of tyrosine hydroxylase in prenatal rat brain. I. Early ontogeny, J. Comp. Neurol., 199 (1981) 233-253

41 Specht, L.A., Pickel, V.M., Joh, T.H. and Reis, D.J., Lightmicroscopic immunocytochemical localization of tyrosine hydroxylase in prenatal rat brain. II. Late ontogeny, J. Comp. Neurol., 199 (1981) 255-276

42 Südhof, T.C. and Jahn, R., Proteins of synaptic vesicles involved in exocytosis and membrane recycling, Neuron, 6 (1991) 665-677

43 Thomas, L. and Betz, H., Synaptophysin binds to physophilin, a putative synaptic plasma membrane protein. J. Cell Biol., 111 (1990) 2041-2052 
44 Thomas, L., Hartung, K., Langosch, D., Rehm, H., Bamberg, E., Franke, W.W. and Betz, H., Identification of synaptophysin as a hexameric channel protein of the synaptic vesicle membrane, Science, 242 (1988) 1050-1053

45 Tixier-Vidal, A., Faivre-Bauman, A., Picart, R. and Wiedenmann, B., Immunoelectron microscopic localization of synaptophysin in a Golgi subcompartment of developing hypothalamic neurons, Neuroscience, 26 (1988) 847-861

46 Trimble, W.S., Gray, T.S., Elferink, L.A., Wilson, M.C. and Scheller, R.H., Distinct patterns of expression of two VAMP genes within the rat brain, J. Neurosci., 10 (1990) 1380-1387

47 Van Lookeren Campagne, M., Oestreicher, A.B., van Bergen en Henegouwen, P.M.P. and Gispen, W.H., Ultrastructural double localization of B-50/GAP43 and synaptophysin (p38) in the neonatal and adult rat hippocampus, J. Neurocytol., 19 (1990) 948-961
48 Verhaagen, J., Oestreicher, A.B., Gispen, W.H. and Margolis, F.L., The expression of the growth associated protein B$50 /$ GAP43 in the olfactory system of neonatal and adult rats, J. Neurosci., 9 (1989) 683-691

49 Wendland, B., Miller, K.G., Schilling, J. and Scheller, R.H., Differential expression of the p65 gene family. Neuron, 6 (1992) 993-1007

50 Wiedenmann, B. and Franke, W.W., Identification and localization of synaptophysin, an integral membrane glycoprotein of $M_{\mathrm{r}}$ 38,000 characteristic of presynaptic terminals, Cell, 41 (1985) $1017-1028$

51 Zhong, C., Hayzer, D.J. and Runge, M.S., Molecular cloning of a cDNA encoding a novel protein related to the neuronal vesicle protein synaptophysin, Biochim. Biophys. Acta, 1129 (1992) 235238 